\title{
DEVELOPMENT OF THE METHOD OF DETERMINING THE TARGET FUNCTION OF OPTIMIZATION OF POWER PLANT
}

\author{
O. Maksymova ${ }^{1}$, M. Maksymov $^{2}$, V. Silina ${ }^{3}$, A. Orischenko ${ }^{4}$ \\ 1,2, 3, 4 Odessa national polytechnical university, Odessa, Ukraine \\ ORCID: ${ }^{1} 0000-0003-3986-0991,{ }^{2} 0000-0002-5626-5265,{ }^{3} 0000-0002-7837-6660,{ }^{4} 0000-0001-7556-7763$ \\ E-mail: ${ }^{1}$ m.oxana.b@gmail.com, ${ }^{2}$ maximov.agro@gmail.com, ${ }^{3}$ vikuskaxxx@gmail.com, ${ }^{4}$ orischenkoa@gmail.com
}

Copyright (C) 2014 by author and the journal - Automation technological and business - processesll.

This work is licensed under the Creative Commons Attribution International License (CC BY).

http://creativecommons.org/licenses/by/4.0/
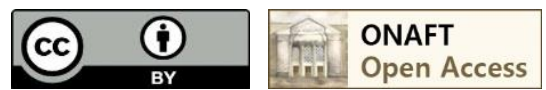

Abstract: It has been proposed the application of an optimization criterion based on properties of target functions, taken from the elements of technical, economic and thermodynamic analyses. Marginal costs indicators of energy for different energy products have also been identified. Target function of the power plant optimization was proposed, that considers energy expenditure in the presented plant and in plants closing the energy sources generation and consumption balance.

Аннотация: Предложено использовать критерий оптимизации, основу которого составляют свойства ичелевых функций, взятых из элементов технико-экономического и термодинамического анализов. Определены показатели замыкаюших затрат энергии на различные виды энергетической продукции. Предложена иелевая функциии оптимизации энергетической установки, учитывающая затрать энергии в рассматриваемую установку, в замыкающие установки, выработку и потребление энергоресурсов, которые изменяются в рассматриваемом варианте.

Keywords: Thermal power plant, operating efficiency, target optimization function, marginal energy costs.

Ключевые слова: Тепловая энергетическая установка, эффективность эксплуатации, целевая функция оптимизации, замыкающие затраты энергии.

\section{Introduction}

Currently methods of efficiency analysis are being developed and applied, based on optimization tasks for various types and modes. Usually, the optimization criterion for these objectives is efficiency that can be calculated in various ways, for which there is no concurrent views.

The target function based on minimization of given cost that allows comparing options with the same useful effect is used to search for the best indicators of power plants operated within the system. Marginal costs on the amount of difference in the useful effect are introduced to the target function in case of various useful effects. The criterion of selecting the best power plant from an economic point of view is the difference between the reduced costs of the considered and the basic options, but this approach does not allow using the results for long-term projections. Such approach depends on the situation and does not reflect the real costs. The value of the target function to optimize the effectiveness of the technical-economic method is not "marginal" and does not allow assessing the impact of various processes on the overall option efficiency.

Therefore, the development of the efficiency criterion that considers the changing needs of the energy system is relevant for analyzing the power plant.

2. Analysis of literature data and problem statement

In [1] it has been considered the problem of search system optimization for parameters of the dynamic protection system of the spacecraft in outer space. It is important to find an acceptable solution between thermal efficiency indicators and the starting value of such a system. Results obtained when solving the problem of determining the optimal parameters of effectiveness of the existing thermal power plants are given in [2]. The obtained results presented a variety of solutions being based on only energy or exergy or exergy-economic indicators. The advantages and disadvantages of their application in optimizing parameters at coal thermal power plants have been demonstrated. The resulting solution showed the advantage of gaseous fuels application in combined cycle and cogeneration power plants compared to coal thermal power plants. In [3] there have been presented results of solving the task for optimum distribution of shares of electric power generation within the power system between the nuclear power stations, renewable energy sources and conventional thermal power plants. In [4] there has been shown the possibility to analyze energy technology objects in close connection with the energy system by the 
optimization criterion that considers properties of both the thermal efficiency indicators and economic feasibility. At this, the control surface includes a system where the considered plant is being operated.

An approach to the optimization of heat exchange equipment based on minimizing life-cycle costs in monetary terms has been proposed in [5]. This method allows to jointly optimize both one-off costs in equipment and operating costs for purification from salt deposits. This approach of searching the efficiency through optimization methods is specific to the large size equipment or the large number of small units.

Work [6] discusses a method of analysis of efficiency and optimization of parameters of biomass combustion process in both the power plant and in the cogeneration plant. The presented approach is used to analyze and optimize management strategies for the energy equipment structure.

In [7] it has been shown that the application of mathematical modeling and pinch analysis makes it possible the application of insolation in combination with the solar thermal system and a heat pump into the conventional power structure of the canning factory. There were analyzed a variety of technological disturbances based on real cases of the production process to determine the effectiveness of this technological scheme. The resulted energy potential of this combination in an industrial process has proved its effectiveness.

The examined material suggests that methods of task programming may be applied to formation of the target function of optimization for different energy technologies according to the criterion of efficiency. Thus, currently there is no single approach to consideration of the power plants performance indicator which simultaneously make provision for energy, economic and energy-economic criteria within the target function of optimization for analysis.

The analysis of literary sources has revealed that the relative energy performance indicators can be used for the formation of the target function of optimization. Analysis of optimization problems solved has shown that it was insufficient to use only the energy or energy-economic criteria of efficiency in the target function because it doesn't account for the system requirement.

Expressions given in [4], using the above criteria, do not give satisfactory results. Moreover, based on these expressions, it is impossible to determine the shortage of one kind of energy production and overproduction of another kind in the system.

At the same time, with another approach it is recommended to use feasibility or other specific indexes to form the target function, for example, costs associated with environmental measures [3, 4].

The account of deficiency or excess of energy production in the target function can be carried out using techno-economic and environmental indicators.

As a rule, the impact of initial arguments on the extremum of the target function in the feasibility and thermodynamic approaches give opposite results. Search of methods for constructing target functions of optimization of power plants for the application of thermoeconomic and thermoecologic analysis for the formation of the efficiency criterion.

Application of thermoeconomic and thermoecologic analyses for the efficiency criterion formation provides more objective results.

In [4] there has been proposed the formation of performance indicators to be carried out in close connection with the energy system. In this case, the control surface includes the energy system, the analyzed plant and the ecological system of emissions rationing.

As a rule, optimization of power plants is carried out by any parameter or group of parameters. The recording method for such a target function is quite simple. Currently, the redundancy of the generated power plants in the system dominates to ensure reliability. The fast change in quantity of the consumed energy production in the system is carried out. In general, more than one plant run within the system. A number of plants can generate various types of energy products. Therefore, the method of determining the target function of optimization should take into account possible changes in the structure of the system consisting of power plants operating for it. This target function must allow performing structural optimization of the currently used plants within the system.

Based on analyses of determinations of the energy flows conversion efficiency in different plants we may conclude as follows: currently, the indicators of operation efficiency of the power plant converting primary energy into the electrical or thermal one are applied. No comparison of conversion efficiency of the fuel used by different plants was carried out. In addition, the systematic demand for energy was not considered in calculations of efficiency. Therefore, further development of methods for searching the performance indicators to optimize the power plants operation within the system is needed.

3. Purpose and objectives of the study

The purpose of the work is to develop a method of determining the target function based on the criterion of operating efficiency of the power plant operating within the system.

The following tasks were to be solved to achieve the set goal:

- development of a method for determining the marginal energy fuel costs;

- development of a method for determining the marginal energy costs on heat and electricity;

- development of performance criteria and formulation of optimization task for the products output at the power plant.

4. Method of determining the marginal energy fuel costs

Marginal energy costs $\varphi_{i}$ consist of two components: capital and operating. The capital component is determined by the energy input on creation of the plant under ecological standards. The range and quantity of materials (steel, concrete, brick, non-ferrous metals, etc.) expended on the project for construction and manufacture of power plant is well known, therefore, the total energy costs can be estimated. Regulatory return rate to capital investment for the new equipment makes $\mathrm{p}=0,15$. The same value will be taken for the energy cost on creating the plant. The rate that takes into account the energy input on current costs when creating a plant is taken numerically the same as the one when determining the technical and economic efficiency. 
Operational component of the marginal energy costs is determined by the amount of primary energy for the plant operation based on the type of fuel burned.

Let's reduce the gaseous, liquid and solid fuel to a common environmental influence. We will take gaseous fuel having a minimal impact on the environment as a base. When using liquid fuel it is necessary to expend the additional amount of primary energy on sulfur and carbon treatment. The combustion of solid fuel takes more energy for ash removal and sulfur retaining. It is necessary to consider the ease of combustion and storage. Obviously, the liquid fuel is most valuable and convenient from this point of view. However, the fuel, both solid and gaseous, can be turned into a liquid (e.g. methanol or LPG).

Based on the above, $1 \mathrm{MJ}$ of liquid fuel energy shall not be equivalent to $1 \mathrm{MJ}$ of solid or gaseous fuels energy. Therefore, when calculating the energy expended for the plant operation, we must enter the relevant fuel type factor.

Since these factors are determined by the amount of energy used for the extraction and processing of fuel, they are of more stable and objective character. We must enter the appropriate coefficients to account the cost of primary energy for transport, production and processing, as well as for compensation of environmental impacts for different types of fuels. First of all, it is necessary to determine costs of primary energy on interconversion of fuels to determine the marginal output of energy for different energy products.

Energy expenditure on solid fuel cleaning can be estimated at $5 \%$, and for purification of liquid fuel at $3 \%$ of the released energy. Expenditure of primary energy for extraction, transport for $1000 \mathrm{~km}$ and processing of various fuels are given in table. 1.

Table 1 - Primary energy expenditure for extraction, transport, processing and interconversion of various fuels

\begin{tabular}{|c|c|c|c|c|c|}
\hline \multirow{2}{*}{ Type of fuel } & \multicolumn{5}{|c|}{ Energy consumption in MJ/t of a reference fuel } \\
\cline { 2 - 6 } & Extraction & Processing & Transport & Gasification & Production \\
\hline Coal & 524 & - & 17,2 & $8,2 * 103$ & $5,3 * 103$ \\
\hline Oil & 364 & 1100 & 8,7 & $15,93 * 103$ & - \\
\hline Natural gas & 108 & - & 16,6 & - & $5,6 * 103$ \\
\hline
\end{tabular}

Coefficients taking into account the substitution of one fuel with another one, will have the form:

$$
\begin{gathered}
K_{l, s}^{\prime}=\frac{Q_{w}^{l, c f}-E_{l 1}-E_{l 2}-E_{l 3}-E_{l 4}}{Q_{w}^{l, c f}-E_{s 1}-E_{s 2}-E_{s 3}-E_{s 4}} \\
K_{g, s}^{\prime}=\frac{Q_{w}^{l, c f}-E_{g 1}-E_{g 2}}{Q_{w}^{l, c f}-E_{s 1}-E_{s 2}-E_{s 3}-E_{s 4}} \\
K_{g, l}^{\prime}=\frac{Q_{w}^{l, c f}-E_{g 1}-E_{g 2}-E_{g 4}}{Q_{w}^{l, c f}-E_{l 1}-E_{l 2}-E_{l 3}-E_{l 4}}
\end{gathered}
$$

where $Q_{w}^{l, c f}=29300 \mathrm{~J} / \mathrm{kg}$ - the lowest calorific value of a standard fuel;

$E_{l 1}, E_{g 1}, E_{s 1}$ - energy for 1 t.s.f. for liquid, solid and gaseous fuel;

$E_{l 3}, E_{s 3}$ - energy consumption for purification of combustion products and removal of liquid and solid fuels residuals:

$E_{g 4}$ - energy expended in the combustion of gaseous fuel;

$E_{s 4}-$ energy expended in the conversion of 1 t.s.f. in coal to liquid fuel;

$E_{s 5}$ - energy expended in 1 t.s.f in coal;

$E_{l 4}$ - energy expended in processing of $1 \mathrm{t}$ of a standard liquid fuel.

Calculation data for $K_{g, s}^{\prime}, K_{l, s}^{\prime}, K_{g, l}^{\prime}$ are given in Table 2.

Table 2 - Substitution ratio of different fuel types

\begin{tabular}{|l|c|c|c|}
\hline Ratio & $K_{l, s}^{\prime}$ & $K_{g, s}^{\prime}$ & $K_{g, l}^{\prime}$ \\
\hline Numeric value & 1,227 & 1,415 & 0,874 \\
\hline
\end{tabular}

When calculating factors given in Table 2, the energy expenditure on mutual substitution of fuels is determined as follows. $8246 \mathrm{MJ} /$ t.s.f is psent at gasification of one ton of solid fuel. It is assumed that the same amount of energy is spent also for gasification of liquid fuel. Reduction of the resulting gases is occurred by converting them to methanol $\mathrm{CH}_{3} \mathrm{OH}$, which process of formation takes place with the release of heat at $400{ }^{\circ} \mathrm{C}$. At an ambient temperature of $290 \mathrm{~K}$ the exergy function of this process makes $\tau_{e}=1-290 /(273+400)=0,43$. 
In the process of methanol production it is evolved $Q_{m}=90804 \mathrm{~kJ} / \mathrm{kmol} \mathrm{CH}_{3} \mathrm{OH}$ of heat, which energy makes $E_{m}=$ $Q_{m} \cdot \tau_{e}=90804 \cdot 0,43=39046 \mathrm{~kJ} / \mathrm{kmol}$.

Let us consider the methanol - gas process where the methane content in gas makes $99 \%$. The calorific value of natural gas $Q_{w}^{1}=39507,0 \mathrm{~kJ} / \mathrm{Nm}^{3}$, at gas density $0,712 \mathrm{~kg} / \mathrm{m}^{3}$. Initially the reaction of methane conversion for the production of methanol is carried out, proceeding with the heat expenditure $\mathrm{CH}_{4}+\mathrm{H}_{2} \mathrm{O}=\mathrm{CO}+3 \mathrm{H}_{3}+195500 \mathrm{~kJ} / \mathrm{kmol}$, and then the reaction of producing methanol $\mathrm{CO}+2 \mathrm{H}_{2}=\mathrm{CH}_{3} \mathrm{OH}-90804 \mathrm{~kJ} / \mathrm{kmol}$ occurs.

As 1 t.s.f. in gas is equivalent to $581 \mathrm{~kg}$ of gas, the expenditure of primary energy on gaseous fuel transformation into the liquid one will make as follows:

$$
Q=\left(\frac{195500}{16}-\frac{90804}{16}\right) \cdot 0,99 \cdot 0,581=5,62 \mathrm{GJ} / \mathrm{t}
$$

Similarly, we can calculate the primary energy expenditure on obtaining methanol from solid fuels.

To determine the marginal energy costs it is necessary to consider the relative thermodynamic efficiency increase resulted from substitution of solid fuel with the liquid or gaseous one and some reduction in costs of energy spent for construction of plants. The relative deterioration of a thermal performance resulted from gas fuel substitution with the liquid one makes $3 \%$ for all types of power plants. Then the real value of the substitution factor for calculating the energy of liquid and gaseous fuels, compared to solid one, is defined as follows:

where $\delta$ - multiplying factor, which is defined as:

$$
K_{l, s}=K_{l, s}^{\prime} \cdot \delta
$$

$$
\delta=\left(\frac{l}{\eta_{s}}\right) \cdot \frac{1+\alpha_{1} \cdot \alpha_{2}}{1+\alpha_{1}},
$$

where $\alpha_{1}$ - a share of the changing variable energy costs for the construction of power plants, depending on the type of fuel combusted; $\alpha_{2}-$ a relative change of the variable part of energy costs for construction of plants when changing the type of fuel combusted.

The substitution factor at the gas fuel combustion compared to the solid one

$$
K_{g, s}=K_{g, s}^{\prime} \cdot \frac{\eta_{g}}{\eta_{s}} \cdot \frac{1+\alpha_{1} \cdot \alpha_{2}}{1+\alpha_{1}}
$$

The substitution factor when replacing the liquid fuel with the gaseous one is defined as follows:

$$
\begin{gathered}
K_{g, l}=K_{g, l}^{\prime} \cdot \delta, \\
\delta=\frac{\eta_{g}}{\eta_{l}} \cdot \frac{1+\alpha_{1} \cdot \alpha_{2}}{1+\alpha_{1}} .
\end{gathered}
$$

Results of calculation of the factor $\delta$ fr various heat consuming enterprises are presented in Table 3 , and factors $K_{g, s}^{\prime}, K_{l, s}^{\prime}$, $K_{g, l}^{\prime}$ in Table 4.

Table 3 - The value of multiplier $\delta$

\begin{tabular}{|l|c|c|c|}
\hline \multicolumn{1}{|c|}{ Indicators } & \multicolumn{2}{c|}{ Consumer } \\
\cline { 2 - 4 } & Boiler-house & TPP & CPP \\
\hline $\begin{array}{l}\text { The relative increase in thermal efficiency when replacing } \\
\text { solid fuel with the gaseous/liquid one }\end{array}$ & $1,120 / 1,086$ & $1,080 / 1,050$ & $1,060 / 1,030$ \\
\hline $\begin{array}{l}\text { The relative change of the variable part in the cost of } \\
\text { energy for construction of enterprises when replacing the } \\
\text { solid fuel }\left(\alpha_{2}\right) / \text { with the gaseous one }\end{array}$ & $1,100 / 1,150$ & $1,050 / 1,080$ & $1,030 / 1,030$ \\
\hline $\begin{array}{l}\text { The value of } \delta \text { when replacing the solid fuel with the } \\
\text { liquid/gaseous one }\end{array}$ & $1,100 / 1,140$ & $1,060 / 1,090$ & $1,03 / 1,070$ \\
\hline
\end{tabular}

Net calorific value of the fuel refers to the energy mass unit of any fuel. 
Table 4 - Values of the substitution factors $K$

\begin{tabular}{|c|c|c|c|}
\hline \multirow[b]{2}{*}{ Indicators } & \multicolumn{3}{|c|}{ Consumer } \\
\hline & Boiler-house & TPP & $\mathrm{CPP}$ \\
\hline $\begin{array}{l}\text { The substitution factor for energy in the transition from solid fuel to } \\
\text { liquid/gaseous one } K_{l, s}^{\prime} / K_{g, l}^{\prime}\end{array}$ & $1,35 / 1,61$ & $1,3 / 1,54$ & $1,26 / 1,51$ \\
\hline $\begin{array}{l}\text { The substitution factor for energy in the transition from liquid fuel } \\
\text { to gaseous one } K_{g, l}^{\prime}\end{array}$ & 0,84 & 0,84 & 0,84 \\
\hline
\end{tabular}

Thus, the proposed method of determining marginal costs of energy for fuel allows considering the different energy value of gaseous, liquid and solid fuels. Such division will further permit to carry out calculations of marginal cost of energy for heat and electricity.

5. Method of determining the marginal energy costs for heat and electricity

Marginal costs of energy consumption for heat and electricity are of local nature and their value depends on the type and performance of thermal generating plants, characteristics of the received energy and of the type of fuel combusted.

Marginal costs of energy $\varphi_{i}$ are determined similarly to marginal costs in economy. This value considers the energy expended for construction and operation of rear plants taking into account the relative energy value of the fuel combusted.

$$
\varphi_{i}=\alpha_{o n} \cdot \alpha_{n l}\left(\frac{\alpha_{r}\left(P E^{e}+U^{e}\right)}{h}+b^{e} \cdot E^{f}\right)+\frac{P E_{d}^{e}+U_{p d}^{e}}{h}
$$

where $\alpha_{o n}, \alpha_{n l}, \alpha_{r}$-factors that consider losses of energy for own needs, losses in networks and power reserves in the power system;

$P$ - regulatory return rate;

$U^{e}-$ constant part of annual energy costs;

$E^{e}-$ specific energy consumption for the plant construction;

$E^{f}$ - energy of the fuel used in the rear plants;

$h$ - annual number of maximum power usage;

$E_{d}^{e}-$ specific energy expenditure on energy distribution;

$b^{e}-$ specific consumption of specific fuel.

Energy expenditure for auxiliary equipment, buildings, structures, etc. are taken into account by a factor of 2 for energy production carrying the base load (units K-300-240 consuming the Donetsk coal). By factor of 3 for gas turbines on natural gas (units GT-150). And by factor of 1.3 for peak water-heating boiler on gas. Data processing allows estimating approximately the weight of the basic equipment for the power of $300 \mathrm{MW}$ in 5300 tons of steel weight of GT-150-180 t, the weight of peak water-heating boiler is 500 tons. The energy expended in the production of the plant's metal was taken to be equal 54,73 $\mathrm{MJ} / \mathrm{kg}$, whereby it is possible to calculate the rear plants' power unit costs.

The numerical values of factors $\alpha_{o n}, \alpha_{n l}, \alpha_{r}$ and the calculated components of the expression (2) are shown in Table 5.

Table 5 -Value of marginal costs of energy for different energy products

\begin{tabular}{|l|c|c|c|c|c|c|c|}
\hline Type of energy products & $\alpha_{o n}$ & $\alpha_{n l}$ & $\frac{\alpha_{r}\left(P E^{e}+U^{e}\right)}{h}$ & $\begin{array}{c}b^{e} \\
\mathrm{kj} / \mathrm{KW} . \mathrm{h}\end{array}$ & $\begin{array}{c}E^{f} \\
\mathrm{kj} / \mathrm{kg}\end{array}$ & $\frac{P E_{d}^{e}+U_{p d}^{e}}{h}$ & $\begin{array}{c}\varphi \\
\mathrm{kj} / \mathrm{KW} . \mathrm{h}\end{array}$ \\
\hline Basic electric power & 1,06 & 1,08 & 190 & 0,326 & 27293 & 113 & 11642 \\
\hline Peak electric power & 1,02 & 1,05 & 100 & 0,43 & 41459 & 70 & 19270 \\
\hline Failed electric power & 1,02 & 1,04 & 190 & 0,34 & 27293 & 10 & 10055 \\
\hline Heat & 1,01 & 1,08 & 200 & 0,144 & 47173 & 223 & 7851 \\
\hline
\end{tabular}

For basic pants $h=7000$ hours/year for peak plants $h=1000$ hours/year, heat supply plants $h=4000$ hours/year. It was assumed that $b^{e}=0,326 \mathrm{~kg}$ of a standard fuel for the base, $b^{e}=0.43 \mathrm{~kg}$ of a standard fuel for peak plants.

It has been assumed for calculations of marginal costs of energy consumption that in a peak water-heating boiler the water in an average winter mode is heated from $60{ }^{\circ} \mathrm{C}$ up to $120{ }^{\circ} \mathrm{C}$. The average ambient temperature in winter is $0{ }^{\circ} \mathrm{C}$. Time of operation in summer is equal to 4100 hours, an ambient temperature $-20^{\circ} \mathrm{C}$, temperature of the direct delivery water is $60^{\circ} \mathrm{C}$ and $40^{\circ} \mathrm{C}$ for the return one. Thermal load in summer for hot water supply system is $30 \%$ of the winter load. 


\section{http://atbp.onaft.edu.ua/}

For boilers with a capacity of $200 \mathrm{MW}$, the annual standard fuel consumption is $V_{R K}=149868,7 \mathrm{t} / \mathrm{year}$, at the efficiency factor of the boiler $\eta_{b o i l}=85 \%$. The total heat production during the year will make $W t=1,037 * 109 \mathrm{~kW}$.h/year. Comply with (1) we will receive cost-based energy for transport $\varphi_{t}^{r k}=7,851 \mathrm{MJ} / \mathrm{kW} . \mathrm{h}$. As seen, the fuel component makes the main contribution to the value of marginal costs of energy per unit of the heat served to the consumer. So, analysis of calculation results associated with the marginal costs of energy per unit of heat released to the consumer makes the fuel component. To calculate the marginal costs of energy for electricity was taken to be the annual number of the installed capacity utilization for basic plants $h=7000$ hours/year, the fuel used is coal. Energy of the mass unit of this fuel is approximately equal to the calorific value; multiplying factors are not introduced in connection with the solid-fuel combustion.

The calorific value per mass unit of the standard solid fuel is reduced from $29,300 \mathrm{~kJ} / \mathrm{kg}$ up to $27,293.3 \mathrm{~kJ} / \mathrm{kg}$. This is due to the energy costs of extraction, transportation of solid fuel and purification of combustion products. The energy expenditure of the plant construction make $E_{b}^{s}=1,933.8 \mathrm{MJ} / \mathrm{kW}$. Marginal costs of energy of basic electricity including the costs of distribution make $\varphi_{b}=11,642 \mathrm{MJ} / \mathrm{kW}$.h.

As for peak power, the energy expenditure on creation of the plant give $E_{p}^{s}=197 \mathrm{MJ} / \mathrm{kW}$.h. Marginal costs of energy of peak electricity, provided gas combustion give $\varphi_{p}=19,270 \mathrm{~kJ} / \mathrm{kWh}$.h. Marginal costs of failed electricity come to $\varphi_{\text {fail }}=$ 10,875кДж/kW.h. (Table 5).

Marginal costs of energy spent on energy products are implicitly the same to marginal costs (R/kW.h) widely used in the feasibility assessment, and reflect not money, but energy categories. Dimension of the marginal costs of energy $=\mathrm{MJ} / \mathrm{MJ}$.

6. Development of performance criteria and formulation of optimization task for product generation by the power plant

Let us consider requirements which the target function should meet. It is advisable to use the main advantages of the energy efficiency index, its " boundedness " and "limitation", since all real processes are irreversible, i.e. are accompanied by energy losses. Value of the efficiency indicator is always less than 1 and greater than 0 ; the obtained useful energy product is always less than the expended primary energy, including cost-based energy on creating a plant and environmental activities. Therefore, the closer the value of the target function to 1 , the better the system utilize the power plant.

Boundary conditions should be adopted to intercompare energy-generating plants by values of the corresponding target function of optimization.

Solution to the optimization task must satisfy the system need. This requirement is met when calculating the performance indicators. Change in settings of the plant scheme changes the ratio between different types of the energy products produced. Consequently, a deficiency or an overproduction of a product must be compensated by change in generation on the closing enterprises. It is necessary to consider systemic demand in failure, baseline and peak electricity in electric power generation. Therefore, it is necessary to compensate for the resulting deficit (or surplus production) of a particular type of energy products in the respective enterprises.

Relative value of the target function should also be considered in addition of different types of energy products. When considering the plant operation within the system, it is advisable to sum up the elaborated peak, basic and failure electric power with certain amendments made. In addition, it is necessary to summarize in the target function the energy expended in the construction and manufacture of the plant with a factor that takes into account the lifetime and energy sources spent on the plant operation.

From the material above it follows, that a performance criterion for the target function of optimization of the power plant operating within the system, taking into account the operation of closing plants and energy cost on their construction, is as follows:

$$
\eta_{e}=\frac{\sum_{j=1}^{n}\left(\sum_{i=1}^{n} E_{i, s y s t}^{*}\right) \tau_{j}}{E_{p} \tau_{\exp }+(p+q) E_{s t r}\left(E_{p}(\tau)\right)+\sum_{i=1}^{n} \Delta E_{i} \Delta \tau_{i} \varphi_{i}}
$$

where $E_{i, s y s t}^{*}$ - power needed to meet systematic demand in the $i$-th type of energy product;

$\tau_{j}$ - time for the system to consume various energy products;

$E_{p}$-heat power of the plant in question;

$\tau_{\exp }$ - operating time of the plant in question;

$\pm \Delta E_{i}$ - deficiency or overproduction of power needed to meet systematic demand in the $i$-th type of energy product [W];

$\Delta \tau_{i}$ - time of overproduction or deficiency of the $i$-th type of energy;

$\varphi_{i}$ - marginal costs of energy spent on the $i$-th type of energy product;

$p$ - regulatory rate of return on the cost of energy for construction;

$q$ - factor that considers the ongoing costs of energy for environmental activities;

$E_{s t r}\left(E_{p}(\tau)\right.$ - energy expended in construction and ensuring ecological measures. 


\section{http://atbp.onaft.edu.ua/}

This expression (3) differs from the previously known performance factors in the fact that addend considering the marginal costs of energy $\varphi_{\mathrm{i}}$ for this particular type of product is introduced in the denominator of the expression.

The target function in the form of (3), made to optimize the power plant that runs within the system, can be upgraded to select the best structure of the system involved. Such an approach on modernization is proposed in [8]. For this, the first term of the denominator is replaced by the sum of energies supplied to the plants involved.

Let us write the general form of the mathematical model for the optimization task of the product generation by a power plant in the form as follows:

$$
\begin{gathered}
f\left(E_{p} ; \Delta E_{1} ; \Delta E_{2} ; . \Delta E_{n} ; E_{s t r} ; \Delta \tau_{1} ; \Delta \tau_{2} ; . \Delta \tau_{n}\right)=\eta \rightarrow \max , \\
\qquad\left\{\begin{array}{l}
\Delta E_{i}<E_{i}, i=\overline{1, n} \\
\Delta \tau_{i}<\tau_{i}, i=\overline{1, n} \\
\tau_{\exp } \geq \sum_{j=1}^{n} \tau_{j} \\
\Delta E_{i}, \Delta \tau_{i}, \tau_{\exp } \geq 0 .
\end{array}\right.
\end{gathered}
$$

Thus, at the very core of the optimization task written is the efficiency criterion for the power plant operation (3). This allows considering both the total systematic demand in all types of energy products, and expenditure of energy on creation, environmental support and operation of the power plant involved, as well as the closing the energy balance plants.

7. Discussing the method of optimization task setting

The main advantage of the obtained method for the optimization task setting is the possibility to analyze the power plant operation within the system to search for its maximum efficiency, which is evidenced in [9]. So, first, it is possible to obtain fair results, as they are based on the objective costs of energy resources but not on their market value bearing an opportunistic nature. Second, it is possible to obtain "limit" and conveniently optimized performance indicator of the power plant within the system. The closer the value of the efficiency criterion to 1 , the more efficient will be the power plant operation within the system. Thirdly, there appears a possibility to compare the operating efficiency of plants with different energy yield. Possibility emerges to compare options of the power plant operation in case of changing its technological parameters. This method does not allow comparing thermal and nuclear power plants operation, as the marginal costs of energy spent on nuclear fuel is not known.

The developed methods for analysis and optimization can be applied to the best solution of any energy production of the distributed type [10]. This method allows to analyze the operation of complexes producing biogas. A further direction of research could be interesting in view of ability to analyze the substitution of gaseous fuel for biogas in power plants. In addition, the proposed method could be of extreme support in optimizing the effectiveness of plants operating on renewable energy sources. So, for wind and solar plants with the very high initial energy costs of their construction, it will be appropriate to record them. However, it is necessary for the plant to define the value of the current capacity, which is random. In addition, the question of impact of such facilities on the environment is under-explored, which makes it difficult finding values of the factor that considers current energy costs spent on environmental activities.

\section{Outputs}

1. The work proposes a method of determining the marginal costs of energy for the fuel. The method is based on the assumption on the necessity of bringing the considered types of fuels to a single energy and ecological effect. The system of coefficients has been proposed, which allows considering the substitution of one fuel by another. The given expressions allow to determine marginal costs of energy for solid, liquid and gaseous fuels. Given for example the calculation of an average value for the marginal costs of solid, liquid and gaseous fuels.

2. The method of determining the marginal costs of energy for heat and electricity has been proposed. Values of the marginal costs of energy for heat and electricity are determined similarly to marginal costs applied in the feasibility analysis. The given expressions allow to determine marginal costs of energy of heat, peak, base and fail electrical energy. The marginal costs of energy for each region take on different meanings and consist of two components: one-time at construction and the annual operational one. Given for example the calculation of an average value for the marginal costs of energy of an energy products.

3. The criterion of efficiency of the power plant operation within the power system has been proposed therein. The criterion is based on properties of the performance criteria taken from elements of the feasibility and thermodynamic efficiency analysis. The property of boundedness and the possibility of adding up different types of energy, considering their different relative value, was used taken from thermodynamic analysis, and the property of consistency and balance of the options under consideration were taken from the feasibility analysis.

The criterion was accepted as the basis for setting the task of optimization the product generation by the power plant. 


\section{References}

\section{http://atbp.onaft.edu.ua/}

[1] Hong-jie Song, Wei Zhang, Ya-qi Li, Zheng-wei Yang, An-bo Ming. (2017) Exergy analysis and parameter optimization of heat pipe receiver with integrated latent heat thermal energy storage for space station in charging process. Applied Thermal Engineering, 119, 304-311.

[2] Ravinder Kumar. (2017). A critical review on energy, exergy, exergoeconomic and econo mic (4-E) analysis of thermal power plants. Engineering Science and Technology, an International Journal, 20, 283-292.

[3] Mehmet Melikoglua. (2016). The role of renewables and nuclear energy in Turkey's Vision 2023 energy targets: Economic and technical scrutiny. Renewable and Sustainable Energy Reviews, 62, 1-12.

[4] Verkhivker G.P.(1986) About thermodynamic comparison and analysis of schemes of energy technological installations. - Izvestiya high schools. Ser.: Power Engineering, 11, 90-93.

[5] Caputo A., Pelagagge P., Salini P. (2011). Joint economic optimization of heat exchanger design and maintenance policy.. Applied Thermal Engineering, 31, 1381-1392.

[6] Strzalka R., Erhart T., Eicker U. (2013). Analysis and optimization of a cogeneration system based on biomass combustion. Applied Thermal Engineering, 50, 1418-1426.

[7] Quijera J., Alriols M., Labidi J. (2014). Integration of a solar thermal system in canned fish factory.Applied Thermal Engineering, 70, 1062-1072.

[8] Pelykh, S.N., Maksimov M.V., Parks G.T. (2013). A method for VVER-1000 fuel rearrangement optimization taking into account both fuel cladding durability and burnup.Nuclear Engineering and Design, 257, 53-60.

[9] Maksimova O.B., Davydov V.O., Babych S.V. (2014). Control of Heat Supply System with Structural Changeable Hardware. Journal of Automation and Information Sciences, v46, i6, 37-48.

[10] Maksimova O.B., Davydov V.O., Babych S.V. (2016). Optimization of Control of Heat Supply Systems of Urban Districts. Journal of Automation and Information Sciences, v48, i4, 69-89.

\section{Литература}

[1] Hong-jie Song. Exergy analysis and parameter optimization of heat pipe receiver with integrated latent heat thermal energy storage for space station in charging process / Hong-jie Song, Wei Zhang, Ya-qi Li, Zheng-wei Yang, An-bo Ming // Applied Thermal Engineering. - 2017. - T. 119. - C. 304-311.

[2] Ravinder Kumar. A critical review on energy, exergy, exergoeconomic and economic (4-E) analysis of thermal power plants / Kumar Ravinder // Engineering Science and Technology, an International Journal. - 2017. - № 20. - C. 283292.

[3] Mehmet Melikoglua. The role of renewables and nuclear energy in Turkey's Vision 2023 energy targets: Economic and technical scrutiny / Mehmet Melikoglua // Renewable and Sustainable Energy Reviews. - 2016. - T. 62. - C. 1-12.

[4] Верхивкер Г.П. О термодинамическом сопоставлении и анализе схем энерготехнологических установок / Г.П. Верхивкер // Известия вузов. Сер.: Энергетика, №11. - С. 90-93.

[5] Caputo A. Joint economic optimization of heat exchanger design and maintenance policy / A. Caputo, P. Pelagagge, P. Salini // Applied Thermal Engineering. - 2011. - № 31. - C. 1381-1392.

[6] Strzalka R. Analysis and optimization of a cogeneration system based on biomass combustion / R. Strzalka, T. Erhart, U. Eicker // Applied Thermal Engineering. - 2013. - № 50. - C. 1418-1426.

[7] Quijera J. Integration of a solar thermal system in canned fish factory / J. Quijera, M. Alriols, J. Labidi // Applied Thermal Engineering. - 2014. - № 70. - C. 1062-1072.

[8] Pelykh S.N. A method for VVER-1000 fuel rearrangement optimization taking into account both fuel cladding durability and burnup / S.N. Pelykh, M.V. Maksimov, G.T. Parks // Nuclear Engineering and Design. - 2013. - T. 257, № 4. - C. 53-60.

[9] Maksimova O.B. Control of Heat Supply System with Structural Changeable Hardware / O.B. Maksimova, V.O. Davydov, S.V. Babych // Journal of Automation and Information Sciences. - 2014. - T. 6, №6. - C. 37-48.

[10] Maksimova O.B. Optimization of Control of Heat Supply Systems of Urban Districts / O.B. Maksimova, V.O. Davydov, S.V. Babych // Journal of Automation and Information Sciences. - 2016. - T. 48, № 4. - C. 69-89. 